\title{
NUCLEAR HUMAN RESOURCE PROJECTION UP TO 2030 IN KOREA
}

\author{
BYUNGJOO MIN ${ }^{\mathrm{a}}$, MANKI LEE ${ }^{\mathrm{a}}$, KEE-YUNG NAM ${ }^{\mathrm{a} 1}$, and KIHO JEONG ${ }^{\mathrm{b}}$ \\ ${ }^{a}$ Korea Atomic Energy Research Institute \\ 150 Dukjindong, Yuseong-gu, Daejeon, 305-338, Republic of Korea \\ ${ }^{b}$ Kyungpook National University \\ Daegu,702-701, Republic of Korea \\ ${ }^{*}$ Corresponding author. E-mail : bjmin@kaeri.re.kr
}

Received January 04, 2011

Accepted for Publication March 29, 2011

The prospects for growth of the nuclear power industry in Korea have improved remarkably as the demand for energy increases in stride with economic development. Meanwhile, as nuclear energy development is enhanced, nuclear technology has also improved evolutionarily and innovatively in the areas of reactor design and safety measures.

As nuclear technology development in Korea advances, more human resources are required. Accordingly, the need for a well-managed program of human resource development (HRD) aimed at assuring needed capacities, skills, and knowledge and maintaining valuable human resources through education and training in various nuclear-related fields has been recognized.

A well-defined and object-oriented human resource development and management (HRD\&M) is to be developed in order to balance between the dynamics of supply and demand of the workforce in the nuclear industry. The HRD\&M schemes include a broad base of disciplines, education, sciences, and technologies within a framework of national sustainable development goals, which are generally considered to include economics, environment, and social concerns.

In this study, the projection methodology considering a variety of economic, social, and environmental factors was developed. Using the developed methodology, medium- and long-term nuclear human resources projections up to 2030 were conducted in compliance with the national nuclear technology development programmes and plans.

KEYWORDS : Nuclear Human Resource Projection, Human Resource Development and Management (HRD\&M)

\section{INTRODUCTION}

The nuclear power and radio-isotope based industries in Korea have been major drivers in the nation's socioeconomic development over the past decades. These industries have also provided spin-offs to technological innovation as well as environmental benefits in terms of avoiding both greenhouse gas emissions and pollution in the context of achieving sustainable development. Furthermore, the country has changed its position from an importer to an exporter of nuclear plants and nuclear technologies.

The history of nuclear energy development in Korea commenced in earnest in 1978 when the first nuclear power plant, Kori-1, was built on a turn-key basis and

${ }^{1}$ Consultant of KAERI; at present Senior Economist in ADB began commercial operation. Nuclear energy was chosen to diversify the nation's energy supply in response to economic development setbacks resulting from the oil crises of the 1970s and 1980s. Twenty nuclear power reactors have been since put into commercial operation, supplying approximately $40 \%$ of Korea's electricity with a total generating capacity of nearly $17.5 \mathrm{GW}(\mathrm{e})$ in 2007 (IAEA, Power Reactor Information System, 2008). Nuclear power has maintained a steady $40 \%$ contribution to the total electricity supply for more than a decade through added new capacity, substantially improved load-factors, and increased efficiencies resulting from improved management and continuous HRD, enforced by increasingly competitive markets.

Korea has accomplished significant scientific and technological development through a national research and development (R\&D) program and international cooperation. Korea's competence in nuclear power and related fuel cycle technologies is building and continues 
to play a significant role in the national future energy supply strategy. The nation has developed the Korean Standard Nuclear Power Plant (KSNP), a pressurized water reactor designed for Ulchin Units 3 to 6 and Yonggwang Units 5 and 6, all of which are in good operation. In addition, a Korean Advanced Pressurised Reactor (APR-1400) is being constructed at Shin-Kori 3 and 4 and Shin-Ulchin 1 and 2.

The experiences accumulated from the operation of the standardized nuclear power plants will enable potential users to explore further innovation. Based on technology and more than twenty years of experience in the construction and operation of nuclear power plants, the Korean nuclear industry is actively developing an overseas nuclear power business aimed at supplying technical engineering services, manufacturing components, construction services, and even the complete building of a Korean-designed reactor. The overseas engineering and technical services are set to cover the plant life cycle including project planning, project management, equipment procurement, commissioning and start-up, operation and maintenance, as well as replacement of major equipment, such as steam generators. Accordingly, Korea may well therefore be a strong competitor in the vendors' and plant suppliers' market in the near future.

In Korea, the vital role of nuclear energy has gained more publicity as the National Energy Committee and announced the 1st Basic Plan of National Energy (BPNE) in August 2008. The BPNE determines the principles and directions of the national energy policy until 2030 taking into consideration of 3Es - Energy security, Energy efficiency, and Environmental protection. It represents five visions of a long term energy policy to face the postfossil fuel era strategically and achieve the ambitious goal of "Low CO2 Emission, Green Growth": (1) Realizing energy independence; (2) Reducing energy consumption by improving energy efficiency; (3) Increasing the supply of clean energy to reduce the use of fossil fuels; (4) Promoting green energy industry; and (5) Ensuring energy accessibility at an affordable price (National Energy Committee: the $1^{\text {st }}$ Basic Plan of National Energy- 20082030). In response, nuclear energy has been reemphasized as an envisaged technology to meet these objectives. According to the plan, the installed capacity of nuclear power will account for 41 percent of the total electricity capacity in 2030, up from 26 percent in 2007, supplying around 59 percent of the nation's total electricity generation.

\section{HUMAN RESOURCE DEVELOPMENT ACTIVITIES}

The success of the Korean nuclear industry is largely the result of a concerted human resource development programme including government sponsored nuclearrelated-training and education for hundreds of persons under the tutelage of companies and countries overseas having experience with nuclear and related sciences and technology. The history of nuclear-related manpower development started in the 1950s when Korea's first wave of nuclear experts (engineers and scientists) was sent to nuclear advanced countries, primarily the US. The returning trainees became advocates for nuclear power in the country and ultimately the core of the nuclear community.

Moreover, Korea has built up its own indigenous expertise to become an effective recipient of technology. To use a plumbing metaphor, the country has created an appropriately sized storage tank to retain the technical know-how and know-why from the supplier, and proper pipelines and optimal pressure need to be maintained between the supplier and recipient. The fill rate depended on recipient preparedness and the nature of the projects. Building up a pool of indigenous expertise required effort and was expensive. This cadre, once repatriated, has formed the nucleus for domestic training and education programmes as an integral part of nuclear energy development and is consistent with national policies.

Forming and developing this cadre was not the result of a training process, but has been well-planned and sustained consistently over time and their expertise has been regularly applied. Experience shows that training without continued application and without long term commitment of a coordinated core of participants and programmes is virtually worthless. HRD\&M must be a dynamic process that includes not only basic education and specific training but also looks to other spin-off learning/industries and to basic inputs/learning as part of the process. The HRD\&M in Korea today comprises an educational network among academic and research institutes, government, and industry.

Over the past three decades, under a national nuclear technology self-reliance programme, Korea has rapidly accumulated extensive experience in nuclear sector development and planning and in nuclear power plant construction and operation. HRD was one of the fundamental bases of this self-reliance policy, under which responsibility for the design, construction, and operation of nuclear power plants in Korea has gradually shifted to domestic organisations, research institutions, and domestic industries, with only limited technological support and technology transfer from foreign subcontractors. Nuclear-related human resource development was crucial not only to nuclear power technology development, but also to nuclear radioisotope-related technologies. These include inter-linked industrial sectors from research reactors for radio-isotope production, nuclear medicine, and non-destructive industrial applications.

The government amended the Atomic Energy Act in 1995 to establish a legal basis to formulate every five years the "Comprehensive Nuclear Energy Promotion Plan (CNEPP)," which includes long-term policy objectives 
and basic directions, sector by sector objectives, and a budget and investment plan for nuclear power. Promoting nuclear human resource development was clearly stated in the second CNEPP, formulated in 2001, as one of the areas in the implementation plan for 2002-2006 to provide direction for nuclear energy policy to the year $2015^{2}$.

Active and continuous engagement of nuclear scientists, engineers, and nuclear-related experts in the localization of nuclear power technology and direct national participation in nuclear power projects have contributed to scientific advancement and furthering the nation's knowledge. This has advanced domestic social and economic development while making Korea one of the world's leading nuclear power countries.

The HRD\&M for the nuclear industry has four prongs: technology transfer and training, university programmes in nuclear-relevant fields, company-sponsored training and project development, and a firm government commitment to developing a nuclear programme and educational and technology spin-offs. The concepts of quality assurance (QA) and quality control (QC) were introduced in the early 1970 s and gradually diffused throughout the Korean nuclear industry and subsequently into other industrial sectors.

Nuclear technology development both requires and fosters HRD. A continuous, consistent, and well-managed programme of HRD is crucial to assure continuity over time in the needed capacities, skills, and knowledge, as well as to establish and maintain a cadre of manpower variously trained in different nuclear-related skills and educated in nuclear relevant fields. Such a programme also fosters the development of spin-off industries and synergies. Productive and goal-oriented HRD\&M is a dynamic long-term process that balances the dynamics of supply and demand of human resources with respect to the education, recruitment, maintenance, and proper training of the human resources needed for industry operations as well as innovation.

Development of a comprehensive HRD\&M policy and strategies for nuclear energy is one of the emerging essential, high priority issues for long-term nuclear energy development in Korea. The prospects for growth of the nuclear power industry in Korea have improved notably in response to the recent launching of the BPNE, as the need for generating capacity grows to meet

\footnotetext{
${ }^{2}$ The ten areas that the implementation plan for 2002-2006 included in CNEPP 2001 promotes are: 1. Nuclear electricity generation and reactor development; 2. Nuclear fuel cycle development; 3. Utilization of radiation and radioisotopes; 4 . Fostering and promotion of the nuclear industry; 5. Enhancement of public understanding and site acquisition; 6. Nuclear safety and radiation protection; 7. Radioactive waste management; 8 . Basic and fundamental nuclear research and development; 9. Training of nuclear manpower; and 10. Nuclear diplomacy and international cooperation.
}

burgeoning energy demand and developmental needs, and as environment, climate change, and energy supply security continue to be matters of rising concern. Nuclear technology itself has also changed, with evolutionary and innovative changes in reactor design and safety measures.

Since a nuclear power programme cannot exist in a void, future HRD\&M schemes for nuclear energy should include a broad base of disciplines, sciences, and technologies, perhaps within a framework of national sustainable development goals, which are generally considered to include economic, environmental, and social concerns. Within this context, areas of interest would include technical performance and nuclear science and engineering, as well as matters related to the economic performance of new nuclear generating capacities compared to alternatives (standards, economics, finance, liability, risks, internalization of externalities), environmental protection (emissions, wastes, decommissioning), social and political issues, energy demand and supply, intergenerational concerns about long-lived wastes and resource depletion, supply security considerations, and innovation.

Moreover, recent concerns about sustainable energy development have added a new dimension to HRD\&M, namely, awareness and accommodation of sustainable development goals. New areas of interest therefore include the environmental sustainability of energy supply and consumption, increased energy efficiency, mobilizing financial resources for expanding energy investments and services, and public sector commitment to consistent national energy, economic, and social development strategies. Energy planning must be linked to goals and priorities in other sectors.

In general, there is no consensus on the future manpower needs of the nuclear industry. Each country will need to arrange its own programme for HRD\&M. Estimates of human resource projection over the next 20 to 25 years vary enormously. Some estimates use as a rule of thumb that the number of needed plant personnel should roughly equal the trend of a plant's megawatt increase, although this does not cover ancillary and fuel cycle requirements.

There are, however, some generally agreed upon principles for the management of HRD in the nuclear industry. As a prerequisite for designing adequate HRD management guidelines and approaches for nuclear HRD\&M, this study focuses on estimating Korea's future nuclear-related manpower requirements, including academic and research institutions, research reactors for isotope production, nuclear medicine, non-destructive industrial applications, and nuclear power generation (design, construction, and operation). The medium and long term nuclear human resources projections developed up to 2030 are not predictions but rather scenarios of plausible ranges of future nuclear human resource projections based on nuclear power generation projections 
reflecting a variety of economic, social, and environmental driving factors. The nuclear human resource projections are derived from a refined input-output analysis based on a review of national nuclear technology development programmes and plans.

\section{FUTURE HUMAN RESOURCE PROJECTION}

\subsection{Methodology and Approaches}

Estimating future human resource projection in nuclearrelated fields requires extensive statistical and economic research. Statistical data gathering and analyses are the backbone and foundation of this study. Because of different data collection requirements, this part of the work was grouped according to sectors, and was initially limited to three major areas: nuclear power, radio-isotopes, and academia. The nuclear power sector includes design, construction, and operation of nuclear power plants as well as nuclear fuel fabrication ${ }^{3}$. The radio-isotope sector includes research reactors for radio-isotope production, nuclear medicine (therapy and diagnosis), and nondestructive industrial applications (food processing, nondestructive testing in industry). The academic sector ${ }^{4}$ includes public and private research and development institutes, and safety institutes ${ }^{5}$.

These sectors were classified as industrial sectors in a refined input-output (I-O) study of the Korean economy to define inter-industry backward and forward linkages and to quantify the human resource projection in the industrial sector from nuclear-related activities. The analysis period covers 2005 to 2030 in five years intervals.

Future human resource projections in the nuclear power and radio-isotope sectors were calculated by multiplying forecasted sales amounts by sector to the respective sectorwise labour coefficients derived from the I-O tables. ${ }^{6}$ In the academic sector, future human resource projection was estimated by specifying regression equations, where explanatory variables are the trend and forecasted nuclear

\footnotetext{
${ }^{3}$ The major institutions in the nuclear power sector are: Korea Power Engineering Company Inc. (KOPEC), Korea Hydro and Nuclear Power Co. (KHNP), Korea Plant Service and Engineering Inc. (KPS), and Korea Nuclear Fuel Co., Ltd. (KNFC).

${ }^{4}$ The major institutions in the academic sector are: Korea Atomic Energy Research Institute (KAERI) and Korea Institute of Nuclear Safety (KINS).

${ }^{5}$ In this study, universities are excluded from the estimation of human resources.

${ }^{6}$ Nuclear Technology and Economic Development in the Republic of Korea, IAEA, 2009 p33

${ }^{7}$ As the explanatory variables include only two variables, trend and nuclear R\&D expenditures, the forecasted human resources in the academic sector is underestimated. Therefore, the forecasted human resources in the academic sector can be interpreted as the minimum required manpower in that sector.
}

$\mathrm{R} \& \mathrm{D}$ expenditures. ${ }^{7}$ The estimated regression equations for the academic sector are as follows:

$$
\begin{aligned}
& \text { Human resources for } \mathrm{R} \& \mathrm{D} \text { institute }= \\
& -29596+15.3 \mathrm{X} 1+0.00070 \mathrm{X} 2 \\
& (-3.39) \quad(3.47) \quad(1.63) \\
& \mathrm{R}^{2}=96.9
\end{aligned}
$$

Human resources for safety institute $=$

$$
\begin{aligned}
& -24692+12.5 \times 1+0.00004 \times 2 \\
& (-3.12) \quad(3.14) \quad(0.12) \\
& R^{2}=93.9
\end{aligned}
$$

where the values in the parentheses represent $t$ values; $\mathrm{X} 1$ is the trend variable and $\mathrm{X} 2$ is nuclear $\mathrm{R} \& \mathrm{D}$ expenditures.

The forecasted sales amount in the nuclear power sector was calculated by multiplying nuclear power generation estimates in the low and high cases (assuming design, construction, and nuclear fuel fabrication costs are all internalized in the nuclear generation cost), by the 2005 electricity sales price of 39.1 won per KWh. Sales in the radio-isotope sector were assumed to be a certain share of the sales amount in nuclear power. The share was $18 \%$ in 2005 and was assumed to show steady growth to $20 \%, 25 \%, 30 \%, 35 \%$, and $40 \%$ in $2010,2015,2020$, 2025 , and 2030, respectively. The medical sector was treated separately and the relation between the sales amount and the Gross Domestic Product (GDP) in 2005 was assumed to be maintained for the entire study period. ${ }^{8}$ The sales amount attributable to radio-isotopes (RI) in the medical sector was calculated by multiplying the sales amount in the medical sector by the RI contribution rate. The latter was calculated as the share of radiation therapy and diagnosis among total medical expenditures, which was $5.56 \%$ in 2005 . The total human resources in the nuclear industry amounted to 43,800 people, as presented in Table 1.

Average labour coefficients for all sectors in 2005 resulted in a value of slightly more than $0.01^{9}$ in response

Table 1. Total Nuclear Human Resource by Sector, 2005 (Unit: persons)

\begin{tabular}{c|c}
\hline Sector & Number of manpower \\
\hline Nuclear power sector & 18,538 \\
\hline Nuclear radio-isotope utilizing sector & 23,808 \\
\hline Academic sector & 1,454 \\
\hline Total & 43,800 \\
\hline
\end{tabular}

${ }^{8}$ The future sales in medical sector are calculated by multiplying GDP by 0.05 .

${ }^{9}$ The meaning of 0.01 is that 10 persons are required per 1 billion won of sales amount. 
to the rapid increases in labour productivity over the past two decades, falling from 0.13 in 1980 and 0.03 in 1990. It is forecasted that a stable further declining trend will continue until it reaches a saturation point at 0.01 in 2010 and remain at that level until the study period (Figure 1).

Korea's rapid economic development has been driven by high rates of domestic savings and investment and a strong emphasis on education, which boosted the percentage of youth enrolled in universities to among the highest in the Organization for Economic Co-operation and Development (OECD) member states. In 2005, Korea had a Gross Domestic Product (GDP) of more than $\$ 790$ billion (in 2000 US $\$$ and exchange rates) and per capita income above $\$ 16,400$. Korea has enjoyed strong economic growth since 1980 , with the exception of 1998 when GDP shrank by $8.6 \%$ in response to the economic crises of 1997 . Output increased by nearly $11 \%$ in 1999 and $9 \%$ in 2000, but slowed in 2001 and subsequent years when overseas demand slackened and as a result of fierce competition in the international market place. Annual average growth rates of GDP are forecast to remain at around 4\% until 2030 (Table 2).

Projections of economic structure by activity are shown in Table 3, with the industrial sector remaining at around $28-29 \%$ during the study period, and the service sector share gaining continuously to approximately $70 \%$.

Possible future development paths for nuclear power were estimated as a business-as-usual (BAU), an alternative (ALT), and a high (HIGH) case, corresponding to a set of contrasting but not extreme assumptions about parameters relevant to the implementation of nuclear programmes. The BAU estimates are based on assumptions that reflect a continuation of present trends: public opposition, enhancement of other nuclear-substituting technologies, moderate economic growth, and institutional and financial funding uncertainties. In this case, the nuclear units under

Table 2. Annual Average Growth Rate of GDP ${ }^{11}$ in Korea, 2005-2030

\begin{tabular}{c|c}
\hline Year & Annual average GDP growth rate \\
\hline 2005 & $5.0 \%$ \\
\hline $2005-2010$ & $4.7 \%$ \\
\hline $2010-2015$ & $4.4 \%$ \\
\hline $2015-2020$ & $4.1 \%$ \\
\hline $2020-2030$ & $4.2 \%$ \\
\hline
\end{tabular}

${ }^{11}$ Until 2020, this was referred to as the $4^{\text {th }}$ Basic Plan of Long-term Electricity Supply and Demand and extrapolated until 2030 based on BPNE.

Table 3. Economic Structural Development ${ }^{12}$, 2005-2030

(Unit: \%)

\begin{tabular}{c|c|c|c|c}
\hline Economic activity & 2005 & 2010 & 2020 & 2030 \\
\hline Agriculture, forestry and fishery & 3.4 & 2.8 & 2.3 & 1.9 \\
\hline Industry & 28.9 & 29.4 & 28.9 & 28.3 \\
\hline Service & 67.5 & 67.7 & 68.6 & 69.7 \\
\hline
\end{tabular}

${ }^{12}$ Ibid.

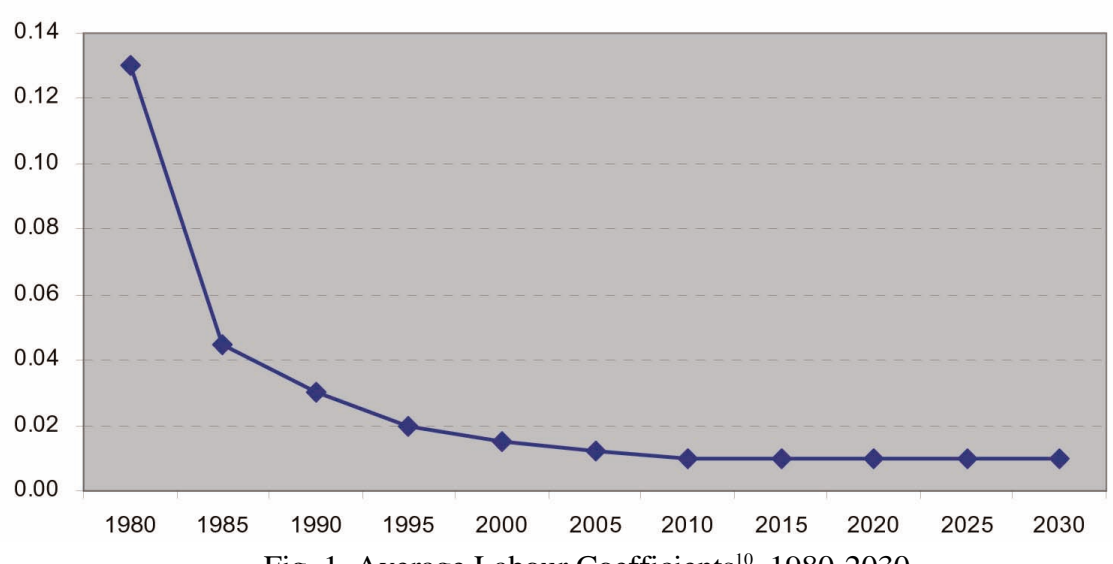

Fig. 1. Average Labour Coefficients ${ }^{10}, 1980-2030$

${ }^{10}$ The labour coefficients were taken from the input-output table published by the Bank of Korea and estimated until 2030. 
Table 4. Estimates of Nuclear Power Generation ${ }^{13}, 2005-2030$

\begin{tabular}{c|c|c|c|c|c|c}
\hline \multirow{2}{*}{ Year } & \multicolumn{3}{|c|}{$\begin{array}{c}\text { Nuclear power } \\
\text { generation (TWh) }\end{array}$} & \multicolumn{3}{c}{$\begin{array}{c}\text { Sales amount of nuclear power } \\
\text { (billion won) }\end{array}$} \\
\cline { 2 - 7 } & BAU & ALT & HIGH & BAU & ALT & HIGH \\
\hline 2005 & 139.3 & 139.3 & 139.3 & $5,446.6$ & $5,446.6$ & $5,446.6$ \\
\hline 2010 & 151.8 & 137.8 & 153.2 & $5,936.9$ & $5,388.6$ & $5,991.9$ \\
\hline 2020 & 216.9 & 237.4 & 256.4 & $8,479.4$ & $9,280.6$ & $10,025.9$ \\
\hline 2030 & 271.7 & 287.5 & 363.5 & $10,625.0$ & $11,242.9$ & $14,214.4$ \\
\hline
\end{tabular}

${ }^{13}$ Sales amount of nuclear electricity was calculated by multiplying the amount of nuclear power generation by the sales unit price determined by KPX (Korea Power eXchange).

Table 5. Estimates of R\&D Expenditure, 2005-2030

\begin{tabular}{c|c|c|c|c}
\multicolumn{1}{c|}{ Scenario } & 2005 & 2010 & 2020 & 2030 \\
\hline BAU & 156.4 & 182.7 & 273.9 & 343.2 \\
\hline ALT & 156.4 & 173.2 & 279.8 & 357.3 \\
\hline HIGH & 156.4 & 183.6 & 308.2 & 443.5 \\
\hline
\end{tabular}

construction will be completed and the nuclear programme that already has won firm commitment will continue to order new units. The ALT estimates are based on the 4th Basic Plan of Long-term Electricity Supply and Demand (BPE), directly reflecting the nuclear expansions until 2017 and extrapolated projections to 2030. The HIGH estimates assume a moderate revival of nuclear power development that could occur in light of a more comprehensive assessment of the macroeconomic and environmental aspects of the different options available for electricity generation. The projected nuclear capacity in Korea in 2030 in the BAU case, ALT case, and HIGH case are approximately $33 \mathrm{GW}(\mathrm{e}), 35 \mathrm{GW}(\mathrm{e})$, and $44 \mathrm{GW}(\mathrm{e})$, respectively.

Table 4 shows the estimates of nuclear power generation and the corresponding estimated expected sales of nuclear power in the three cases through 2030.

Future R\&D expenditures are also estimated on the basis of future nuclear power generation, since funding for this $R \& D$ is fixed at a constant value of 1.2 won per KWh through current power policy and regulations (see Table 5).
Table 6. Estimates of Human Resource Requirements in Nuclear Power Sector, 2010-2030

\begin{tabular}{c|c|c|c}
\hline Year & BAU & ALT & HIGH \\
\hline 2010 & 19,126 & 17,360 & 19,304 \\
\hline 2020 & 27,317 & 29,898 & 32,299 \\
\hline 2030 & 34,229 & 36,220 & 45,793 \\
\hline
\end{tabular}

Table 7. Estimates of Human Resource Requirements in Radio-isotope Sector, 2010-2030 ${ }^{14}$

(Unit: persons)

\begin{tabular}{c|c|c|c|c|c|c}
\hline \multirow{2}{*}{ Year } & \multicolumn{3}{|c|}{ Industrial sector } & \multicolumn{3}{c}{ Medical sector } \\
\cline { 2 - 7 } & BAU & ALT & HIGH & BAU & ALT & HIGH \\
\hline 2010 & 2,580 & 2,342 & 2,604 & 21,307 & 21,307 & 21,307 \\
\hline 2020 & 5,528 & 6,051 & 6,537 & 32,305 & 32,305 & 32,305 \\
\hline 2030 & 9,236 & 9,773 & 12,357 & 46,234 & 46,234 & 46,234 \\
\hline
\end{tabular}

${ }^{14}$ Based on the assumption of the analysis, there is no difference in the medical sector for all scenarios.

\subsection{Results and Discussion}

Based on the relevant data and assumptions, the nuclear-related human resource projections up to 2030 for the nuclear power and RI sectors are estimated. These values are calculated as integer variables related to the sales of nuclear power and RI. Besides these direct human resource requirements, induced manpower needs arising from all relevant and related sectors were also estimated, however they are not included in this paper

In the nuclear power sector, human resource projection includes manpower directly employed in companies/ institutions designing, constructing, and operating nuclear power plants as well as in nuclear fuel fabrication. Induced manpower is engaged in other interlinked industrial sectors (see Table 6). A similar calculation is made for the RI sector (Table 7). In this sector, induced manpower is very high compared to direct manpower requirements, reflecting the rapid development of RI technology in line with the expansion of non-electric nuclear applications. In the academic sector, by contrast, the calculated human resource projection is very small since no output effect or induced effect is discernible in the GDP (Tables 8, 9, and 10).

The total human resource projections for the three cases as estimated are presented in Tables 11, 12, and 13. 
Table 8. Estimates of Human Resource Requirements in Academic Sector, 2010-2030 (BAU case)

(Unit: persons)

\begin{tabular}{c|c|c|c}
\hline Year & Research & Safety & Total HR requirements \\
\hline 2010 & 1,200 & 420 & 1,620 \\
\hline 2020 & 1,415 & 549 & 1,963 \\
\hline 2030 & 1,615 & 677 & 2,291 \\
\hline
\end{tabular}

Table 9. Estimates of Human Resource Requirements in Academic Sector, 2010-2030 (ALT case)

(Unit: persons)

\begin{tabular}{c|c|c|c}
\hline Year & Research & Safety & Total HR requirements \\
\hline 2010 & 1,194 & 419 & 1,613 \\
\hline 2020 & 1,419 & 549 & 1,968 \\
\hline 2030 & 1,624 & 677 & 2,301 \\
\hline
\end{tabular}

Table 10. Estimates of Human Resource Requirements in Academic Sector, 2010-2030 (HIGH case)

(Unit: persons)

\begin{tabular}{c|c|c|c}
\hline Year & Research & Safety & Total HR requirements \\
\hline 2010 & 1,201 & 420 & 1,621 \\
\hline 2020 & 1,438 & 550 & 1,988 \\
\hline 2030 & 1,683 & 681 & 2,364 \\
\hline
\end{tabular}

The direct requirements are the actual human resource projection for the nuclear industries themselves. ${ }^{15}$ Induced manpower requirements are those for nuclearrelated industries and services. From an economic analytical point of view, it is important to derive the induced manpower, as a certain portion of the manpower can be considered as potential candidates for nuclear human resource development.

\footnotetext{
${ }^{15}$ The figure for manpower in the nuclear power sector in 2005 is the sum of manpower from major nuclear power specific companies (total of 12,341, of which 7,500 from KHNP, 629 from KNFC, 300 from KOPEC and 3,912 from KPS) and from other companies supporting the nuclear power sector including financing. The amount of manpower specific to nuclear power in 2005 accounts for around $67 \%$.
}

Table 11. Estimates of Total Human Resource Requirements by Sector, 2005-2030 (BAU case)

\begin{tabular}{c|c|c|c|c}
\hline Sectors & 2005 & 2010 & 2020 & 2030 \\
\hline Nuclear power sector & 18,538 & 19,126 & 27,317 & 34,229 \\
\hline $\begin{array}{c}\text { Nuclear radio-isotope } \\
\text { utilizing sector }\end{array}$ & 23,808 & 23,887 & 37,833 & 55,470 \\
\hline Academic sector & 1,454 & 1,620 & 1,963 & 2,291 \\
\hline Total & 43,800 & 44,633 & 67,114 & 91,990 \\
\hline
\end{tabular}

Table 12. Estimates of Total Human Resource Requirements by Sector, 2005-2030 (ALT case)

(Unit: persons)

\begin{tabular}{c|c|c|c|c}
\hline Sectors & 2005 & 2010 & 2020 & 2030 \\
\hline Nuclear power sector & 18,538 & 17,360 & 29,898 & 36,220 \\
\hline $\begin{array}{c}\text { Nuclear radio-isotope } \\
\text { utilizing sector }\end{array}$ & 23,808 & 23,649 & 38,356 & 56,007 \\
\hline Academic sector & 1,454 & 1,613 & 1,968 & 2,301 \\
\hline Total & 43,800 & 42,622 & 70,222 & 94,528 \\
\hline
\end{tabular}

Table 13. Estimates of Total Human Resource Requirements by Sector, 2005-2030 (HIGH case) (Unit: persons)

\begin{tabular}{c|c|c|c|c}
\hline Sectors & 2005 & 2010 & 2020 & 2030 \\
\hline Nuclear power sector & 18,538 & 19,304 & 32,299 & 45,793 \\
\hline $\begin{array}{c}\text { Nuclear radio-isotope } \\
\text { utilizing sector }\end{array}$ & 23,808 & 23,911 & 38,842 & 58,590 \\
\hline Academic sector & 1,454 & 1,621 & 1,988 & 2,364 \\
\hline Total & 43,800 & 44,835 & 73,129 & 106,747 \\
\hline
\end{tabular}

The results of the analysis show that the human resources projection for radio-isotope applications are the highest, with an annual average growth rate of $3.3 \%$, $3.4 \%$, and $3.6 \%$ for BAU, ALT, and HIGH cases, respectively, accounting for more than $55 \%$ of the total nuclear human resources projection in the period of 2005-2030. In all cases, the future nuclear industry requires more than double the amount of human resources by 2030 as compared to 2005 , in line with sustainable nuclear industry development in Korea (see Figure 2). 


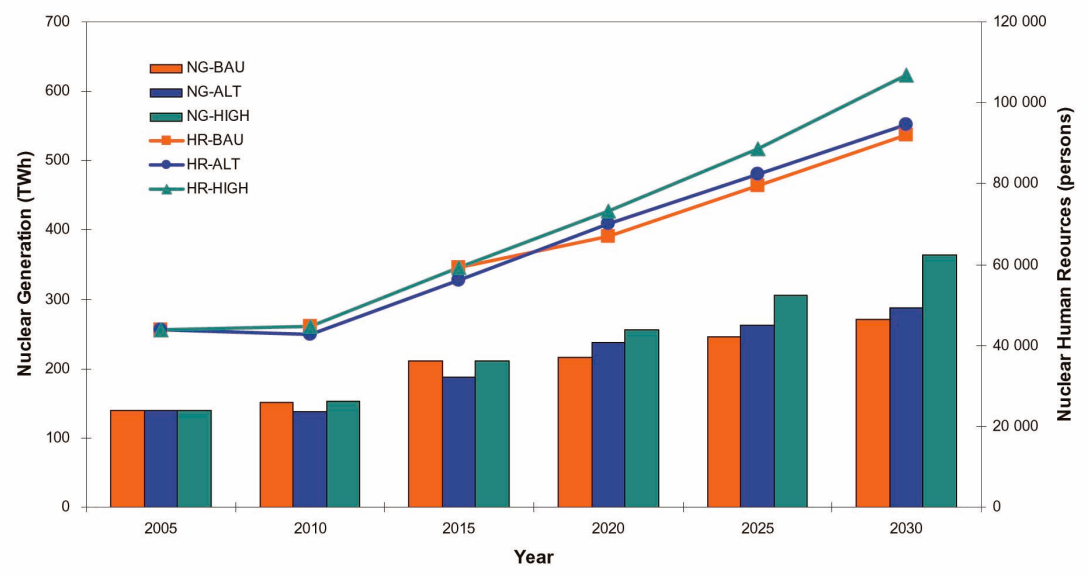

Fig. 2. Total Nuclear Human Resource Requirements, 2005-2030 (BAU, ALT and HIGH case)

\section{CONCLUSION}

The purpose of this study was to develop an appropriate quantitative basis for the future HRD management guidelines and approaches for nuclear-related HRD\&M that are consonant with sustainable economic, social, and environmental development. Industrial and economic growth as currently forecast will entail greater use of nuclear technologies for power generation, medicine, and industrial applications. Assuring a continued quality supply of these services will require, among other things, a continuous, consistent, and well-managed programme of HRD to assure continuity over time in the needed capacities, skills, and knowledge needed for industry operations as well as innovation.

In Korea, a high priority issue is the establishment of a comprehensive human resource development and management (HRD\&M) policy and strategies for longterm nuclear technology development. This requires a long term commitment of a coordinated core of participants and programmes supported by the government, private companies, universities, and research institutions. Enhanced public-private partnership and international collaboration will certainly play a significant role for nuclear development and educational and technology spin-offs in Korea.

Although the primary elements of the dynamic HRD\&M include recruiting, development/maintaining, and retention, well-systematized knowledge capture is vital to development. Ideally, a process should be in place for recording employee knowledge and skills on an ongoing basis such as through the development of systematized databases. In this respect, the Human
Resource Development Centre (HRDC) in Korea Atomic Energy Research Institute (KAERI) has been a focal point for the nuclear-relevant HRD\&M. With a well-honed HRD programme to train experts in a broad spectrum of nuclear-related fields and through coordination of such programmes at the national and international levels, the HRDC will continue to play a leading role in this regard.

\section{REFERENCES}

[ 1 ] B.J., Min, "KAERI's Nuclear Training Programme", The $24^{\text {th }}$ KAIF/KNS Annual Conference, Seoul, Korea, 2009.

[2] M.K., Lee, K.Y., Nam, K.H., Jeong, B.J., Min, "Contribution of Nuclear Power to the National Economic Development in Korea", NET, Vol.41 No.4, May 2009.

[3] B.J., Min, "The Prospects of Korean HRD in Nuclear Technologies", the 23th KAIF/KNS Annual Conference, Seoul, Korea, 2008.

[4] B.J., Min, "The Status \& Prospects of Korean HRD in Nuclear Technologies", National Nuclear Symposium in Japan, 2008.

[5] B.J., Min, H., Kwon, "Future Prospects of Human Resources in Asian Industry", Regional workshop on managing Nuclear Knowledge, Japan, 2007

[6] B.J., Min, "Future Perspectives of Human Resources in Nuclear Technologies - the Korean case", Int'l conf. On Knowledge management in nuclear Facilities, IAEA, Vienna, Austria, 2007

[7] The $1^{\text {st }}$ Basic Plan of National Energy (BPNE), 2008.

[ 8 ] Comprehensive Nuclear Energy Promotion Plan (CNEPP), 2001

[9] Nuclear Technology and Economic Development in the Republic of Korea, IAEA, 2009 p33

[10] The $4^{\text {th }}$ Basic Plan of Long-term Electricity Supply and Demand, 2008 